\title{
Imaging Pregnant Patients in Different Acute Medical Non-Traumatic Emergencies. A Literature Review.
}

\author{
${ }^{1}$ Behar Tocilla \\ https://doi.org/10.32391/ajtes.v4i1.85
}

\begin{abstract}
Radiologists should suggest what kind of imaging is best suited for a pregnant patient presenting with an acute condition. The type of imaging study is planned in close consultation with the clinical team. Ultrasonography (US) should always be the initial modality for evaluation of a pregnant patient, especially in abdominal emergencies. In other conditions like suspected pulmonary embolism or neurological emergencies ultrasound doesn't help, so using other diagnostic modalities like CT and MRI will be necessary. A recurring debate in many radiology practices is the concern of radiologists about performing an examination that exposes a fetus to radiation. This literature review aims to identify an optimal imaging strategy for the accurate detection of different acute medical non-traumatic emergencies in pregnant patients. Keywords: pregnancy, imaging, non-traumatic emergencies, US, MRI, CT
\end{abstract}

${ }^{*}$ Corresponding Author: Behar Tocilla

=四 E-mail: behartocilla@yahoo.it

${ }^{1}$ Radiology Department, American Hospital, Tirana, Albania 


\section{Full Text}

\section{Introduction}

Radiologists should suggest what kind of imaging is best suited for a pregnant patient presenting with an acute condition. The type of imaging study is planned in close consultation with the clinical team. Ultrasonography (US) should always be the initial modality for evaluation of a pregnant patient, especially in abdominal emergencies. In other conditions like suspected pulmonary embolism or neurological emergencies ultrasound doesn't help, so using other diagnostic modalities like CT and MRI will be necessary.

A recurring debate in many radiology practices is the concern of radiologists about performing an examination that exposes a fetus to radiation. A recent literature review demonstrated that in general, there is a lower than expected awareness of radiation risks associated with imaging pregnant women both among radiologists and among clinicians.

\begin{tabular}{|l|l|l|l|}
\hline \multirow{2}{*}{$\begin{array}{l}\text { Gestational Age } \\
\text { (weeks) }\end{array}$} & \multicolumn{3}{|c|}{ Potential Effects by Radiation Exposure } \\
\cline { 2 - 4 } & $\begin{array}{c}<50 \\
\mathrm{mGy}\end{array}$ & $50-100 \mathrm{mGy}$ & \multicolumn{1}{|c|}{$>100 \mathrm{mGy}$} \\
\hline $0-2$ & None & None & None \\
\hline $3-4$ & None & Probably none & Possible spontaneous abortion \\
\hline $5-10$ & None & Uncertain & $\begin{array}{l}\text { Possible malformations } \\
\text { Possible deficits in IQ or mental } \\
\text { retardation }\end{array}$ \\
\hline $1-17$ & None & Uncertain & $\begin{array}{l}\text { Q deficits not detectable at diagnostic } \\
\text { doses }\end{array}$ \\
\hline $8-27$ & None & None & $\begin{array}{l}\text { None applicable to diagnostic } \\
\text { medicine }\end{array}$ \\
\hline$>27$ & None & None & Ry Gestational Age and Radiation \\
\hline
\end{tabular}

Table 1: Potential Radiation Effects on the Fetus by Gestational Age and Radiation

Exposure

\section{Radiation Effects}

The effects of radiation exposure have been studied extensively and the risks of radiation can be categorized as stochastic and nonstochastic effects.

\section{Stochastic Effects}

Stochastic effects are the result of cellular damage, likely at the DNA level, causing cancer or other germ cell mutation. Stochastic effects have no threshold value and are theorized to occur with exposure to any amount of ionizing radiation. The severity of radiation-induced stochastic effects is independent of the radiation dose. Historically, the radiation dose estimated for stochastic effects, as based on probability, was established at 50 mGy (5 rad) ${ }^{1-4}$

American College of Radiology (ACR) produced practice guidelines for imaging pregnant patients and provided an approximation of fetal risk at various gestational ages with differing radiation exposure (Table 1) 5,6 
As shown in Table 1, the ACR suggested that theoretical risks are not likely at doses less than 100 mGy (10 rad). ${ }^{7}$

\section{Nonstochastic Effects}

Nonstochastic effects (threshold effects) are caused by exposure to radiation at high doses. These effects are predictable and involve multicellular injury, which can include chromosome aberrations. Threshold effects follow a linear progression, with risk increasing with increasing dose ${ }^{2,4}$ ).
Historically, the threshold dose has been estimated to be $150 \mathrm{mGy}$ (15 rad) (8). At this dose, it is recommended for the pregnancy to be terminated.

Table 2 shows the average values for fetal radiation dose after a single acquisition for various CT examinations in pregnant patients. Given the low radiation exposure, fear of fetal radiation exposure should not delay imaging studies that may help identify underlying maternal pathologic conditions. 2,4,5,9

\begin{tabular}{|l|c|l|c|}
\hline Examination & $\begin{array}{c}\text { Estimated Fetal } \\
\text { Dose }(\boldsymbol{m G} \boldsymbol{y})\end{array}$ & \multicolumn{2}{l|}{ CT Estimated Fetal Dose } \\
\hline Radiography & & Head & 0 \\
\hline Cervical spine (AP, lateral) & $<0.001$ & Chest (routine) & 0.2 \\
\hline Extremities & $<0.001$ & $\begin{array}{l}\text { Chest (pulmonary } \\
\text { embolism protocol) }\end{array}$ & 0.2 \\
\hline Chest (PA, lateral) & 0.002 & Abdomen & 4 \\
\hline Thoracic spine & 0.003 & Abdomen and pelvis & 25 \\
\hline $\begin{array}{l}\text { Abdomen (AP) (21-cm } \\
\text { patient thickness) }\end{array}$ & 1 & $\begin{array}{l}\text { CT angiography of } \\
\text { The aorta }\end{array}$ & 34 \\
\hline $\begin{array}{l}\text { Abdomen (AP) (33-cm } \\
\text { patient thickness) }\end{array}$ & 3 & $\begin{array}{l}\text { CT angiography of the } \\
\text { coronary arteries }\end{array}$ & 0.1 \\
\hline Lumbar spine (AP, lateral) & 1 & & \\
\hline
\end{tabular}

Table 2: Estimated Fetal Radiation Dose from Conventional Radiographic and CT

\section{Examinations}

Imaging Pregnant Patients with Suspected Pulmonary Embolism

A diagnosis of pulmonary embolism in pregnancy has important implications, including the need for prolonged anticoagulation therapy, delivery planning, and possible prophylaxis during future pregnancies, as well as concern about future oral contraceptive use and estrogen therapy. 10-13,16

The clinical pathway for evaluating pregnant patients with suspected pulmonary embolism has been a topic of debate. 13-15 In the absence of standard guidelines, there is aneed to familiarize radiologists with the relative advances and limitations of various tests used.

This category of patients is a real challenge for the clinician because classic clinical symptoms are often absent and physiologic changes during pregnancy can mimic pulmonary embolism eg, leg swelling, pain, dyspnea, tachypnea, tachycardia, 
palpitations. Also, the pregnancy itself has increased risk for thrombosis and sometimes has elevated levels of Ddimer.

The clinical awareness in pregnant patients for pulmonary embolism is low. Frequency of diagnosis of venous thromboembolism in (A) nonpregnant and (B) pregnant patients in a meta-

analysisis shown in table 3. The frequency of $\mathrm{VTE}+$ diagnosis among 24,833 nonpregnant patients was $12.4 \%$ (95\% CI $=9.0 \%$ to $16.3 \%, \mathrm{I}^{2}=0 \%$ ), and the frequency of VTE+ diagnosis among the 506 pregnant patients was $4.1 \%\left(95 \% \mathrm{CI}=2.6 \%\right.$ to $\left.6.0 \%, \mathrm{I}^{2}=0 \%\right) .{ }^{17}$

Proportion meta-analysis plot [random effects]

Proportion meta-analysis plot [random effects]

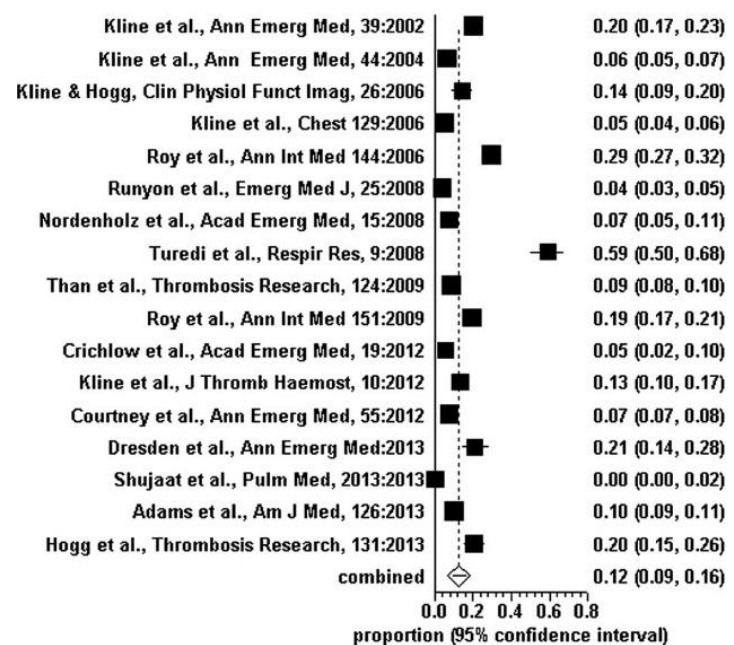

Table 3: Diagnosis of PE in pregnant and nonpregnant patients.

In the ED setting, physicians test for PE in pregnant patients at a low threshold, resulting in a low rate of VTE diagnosis and a RR of VTE that is lower than that for childbearing age who are tested for PE in the ED setting.

A diagnostic algorithm for suspected PE in pregnancy guideline from Society of Thoracic Radiology Clinical Practice is shown in figure $1 .{ }^{17}$ 


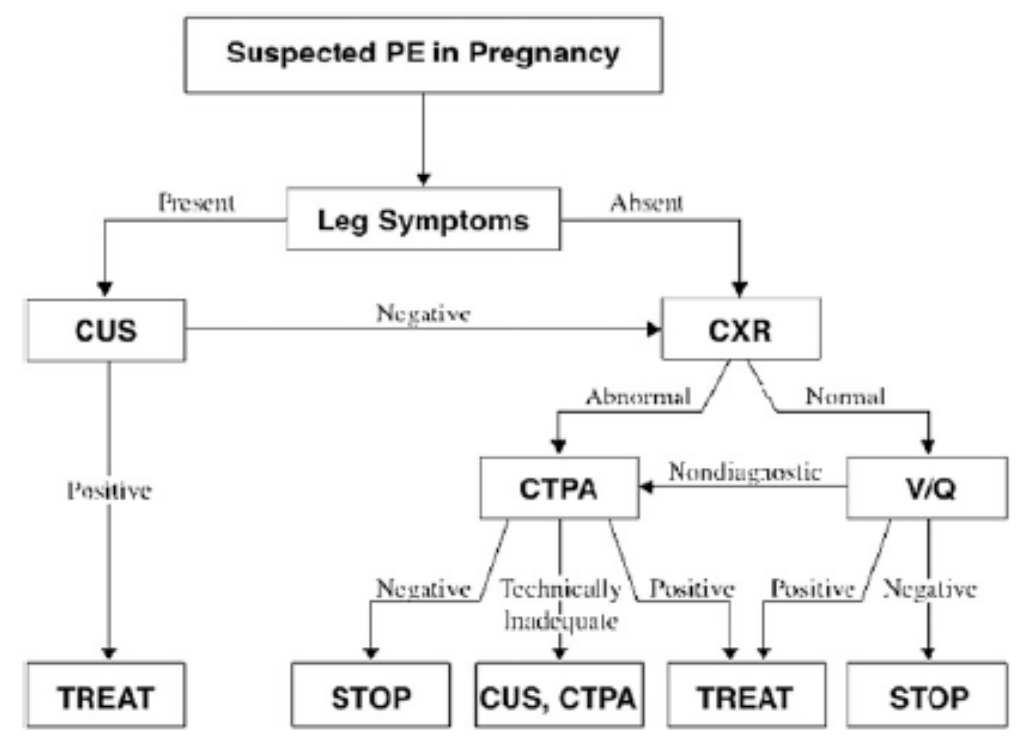

Figure 1: Algorithm for suspected PE.

Recommendations that comes on based on the algorithm: 17

Recommendation 1.

In pregnant women with suspected $\mathrm{PE}$, we suggest that D-dimer not be used to exclude PE (weak recommendation, very-low-quality evidence).

Recommendation 2.

In pregnant women with suspected PE and signs and symptoms of deep venous thrombosis (DVT), is suggested performing bilateral venous compression ultrasound (CUS) of lower extremities, followed by anticoagulation treatment if positive and by further testing if negative (weak recommendation, very-low-quality evidence).

\section{Recommendation 3.}

In pregnant women with suspected $\mathrm{PE}$ and no signs and symptoms of DVT, is suggested performing studies of the pulmonary vasculature rather than CUS of the lower extremities (weak recommendation, very-low-quality evidence).

Recommendation 4.

In pregnant women with suspected PE, is recommended a CXR as the first radiation-associated procedure in the imaging work-up (strong recommendation, low-quality evidence).

Recommendation 5.

In pregnant women with suspected $\mathrm{PE}$ and a normal CXR, is recommended lung scintigraphy as the next imaging test rather than CTPA (strong recommendation, low-quality evidence).

Recommendation 6.

In pregnant women with suspected PE and a nondiagnostic V/ Q scan, is suggested further diagnostic test- ing rather than clinical management alone (weak recommendation, low-quality evidence). In patients with a nondiagnostic V/ Q scan in whom a decision is made to further investigate, 
is recommended CTPA rather than DSA (strong recommendation, verylow-quality evidence).

Recommendation 7.

In pregnant women with suspected $\mathrm{PE}$ and an abnormal CXR, is suggested CTPA as the next imaging test rather than lung scintigraphy (weak recommendation, very-low-quality evidence)

Based on recommendations above, none of them was statistically superior to others. In making recommendations and considering their strength, the panel placed a higher value on minimizing radiation dose and a lower value on test rapidity, test potential to provide alternate diagnosis, and cost.

What are the risks to mother and fetus when diagnostic studies requiring radiation are performed?

Table 4 shows measured radiation doses to fetus and mother associated with diagnostic tests for suspected PE in pregnancy. 17

\begin{tabular}{lcc}
\hline Diagnostic Test & Fetal Dose (mGy) & $\begin{array}{c}\text { Maternal Dose (Whole Body } \\
\text { Effective Dose in mSv) }\end{array}$ \\
\hline CXR & 0.002 & 0.1 \\
V/Q் & $0.32-0.74$ & $1-2.5$ \\
CTPA & $0.03-0.66$ & $4-18$ \\
\hline DSA & - & $7-28$ \\
\hline
\end{tabular}

Table 4: Fetal and maternal radiation doses associated with diagnostic tests for pulmonary embolism

Studying the table above we see that the radiation doses for fetus are greater in scintigraphy than in CT.

Based on the availability of scintigraphy which doesn't work 24 h/day, when none of diagnostic modalities was statistically superior to others and with new CT following protocols radiation doses are maintained under 50 mGy (doses vary from $8-14 \mathrm{mSv}$ and can be calculated automatically from CT in the end of exam) diagnostic algorithm can be simplified like in figure 2.

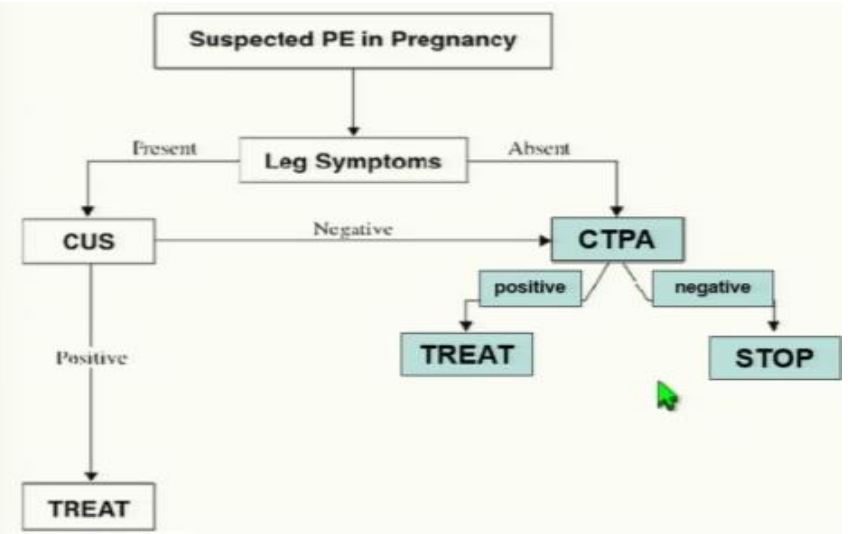

Figure 2: Algorithm for suspected PE in pregnant patients simplified. 
It is important to note that there is an estimated 30-630-fold greater breast dose with CT pulmonary angiography (10-70 mGy) than with low-dose perfusion scintigraphy, with breast dose values well above the traditional 3 mGy used in screening mammography and equivalent to exposure from hundreds of chest radiographs (17-20). Which is the most appropriate protocol for CTPA?

During pregnancy there are some hemodynamically changes like increase in blood volume, cardiac output dhe cardiac frecuency. All of them produce an increase at about sixfold the "thoracoabdominal pump" in supine position and in full inspiration. This can create a" transient interruption of contrast", which suggest PE (false positive) (figure 3). It happens until 39 $\%$ of patients not following the right protocols.

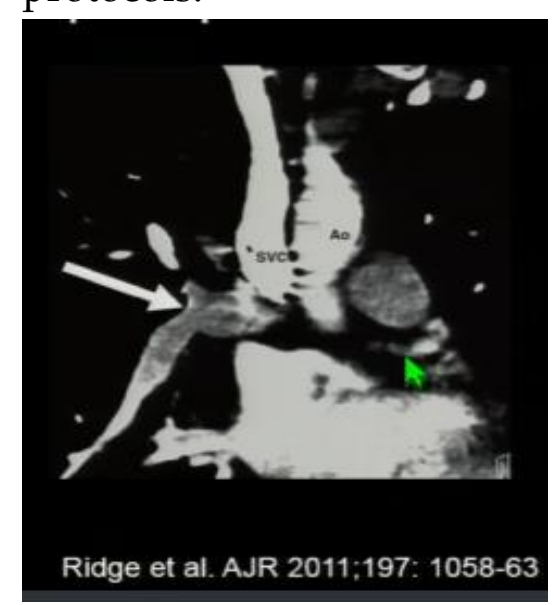

Figure 3: Trasient interruption of contrast because of deep Valsalva.

Methods of Reducing the Radiation Dose to the Maternal Breast and Fetus at CT Pulmonary Angiography 17

Thin-layer bismuth breast shield
Lead shielding

Reduction in tube current $(70-80 \mathrm{kVp})$

Reduction in tube voltage

Increase in pitch

Increase in detector collimation thickness

Reduction of $\mathrm{z}$-axis

Also because of high cardiac output we should perform high speed of contrast injection $(5 \mathrm{ml} / \mathrm{s})$, high levels of contrast concentration (350-400 mg/ml).

No Valsalva

Elimination of lateral scout image

Fixed injection timing rather than test run

Elimination of any additional CT sequences

Early scaning but nor flash mode.

\section{Acute abdomen and appendicitis}

Clinical diagnosis of the cause of abdominal pain in a pregnant patient is particularly difficult because of multiple confounding factors related to normal pregnancy. Such confounding factors include nonspecific leukocytosis, displacement of abdominal and pelvic structures from their normal locations by the gravid uterus, a difficult abdominal examination, and nonspecific nausea and vomiting. ${ }^{21,22}$

During the second and third trimesters of pregnancy, the gravid uterus increases in size and displaces the pelvic contents from their normal locations.

In the same way like in PE is difficult the definition of absolute indication for diagnostic imaging. 
Ultrasonography (US) is considered the imaging study of choice for evaluation of abdominal pain in pregnant patients, MR imaging is a valuable adjunct to US in evaluation of pregnant patients with acute right lower quadrant (RLQ) pain who have inconclusive US results. CT should not be used because the radiation damages the embryogenesis and can cause carcinogenesis. CT can be performed in the second and third trimesters if MR imaging is unavailable or if there is lack of expertise (figure 4). 5

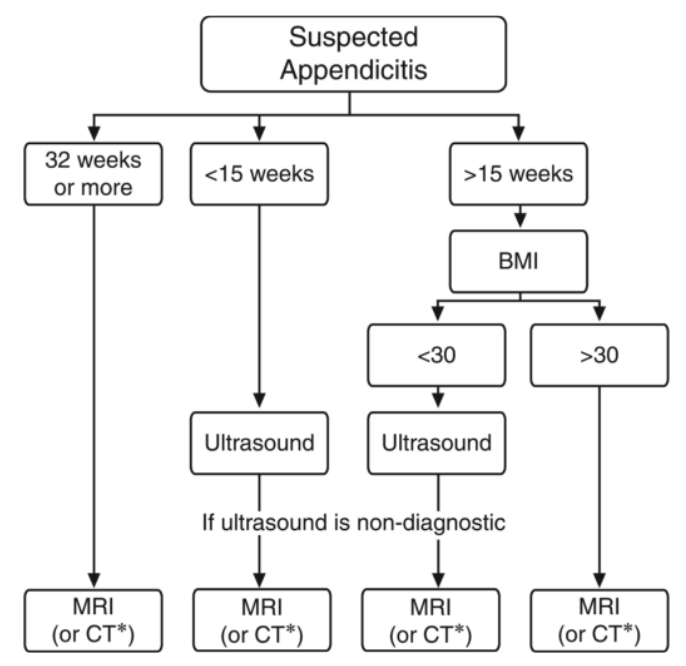

Figure 4: Algorithm for work-up of right lower quadrant abdominal pain in a pregnant patient when there is a strong suspicion of appendicitis. BMI = body mass index, * = use CT if MR imaging is unavailable.
MR examination is thought to be safe in pregnancy and can be used regardless of the trimester when the outcome of the examination has the potential to affect the care of the patient. Examinations are performed at a field strength of $1.5 \mathrm{~T}$ with the patient in the supine position and with a body phased-array coil. Intravenous contrast agents are not used.

The MR imaging protocol for pregnant patients is detailed in table 5. Singleshot fast SE images are acquired in the three orthogonal planes (axial, coronal, and sagittal). Single-shot imaging provides a motion-insensitive strategy even in the presence of severe fetal motion.

Axial single-shot fast SE images with frequency-selective fat saturation pulses improve the detection of inflammatory changes and edema.

Axial TOF GRE T2*-weighted images are used to differentiate the normal appendix from the

commonly seen dilated venous tributaries of the right gonadal

Axial T1-weighted inphase and opposed-phase GRE images are valuable to identify hemorrhagic and fat-containing lesions. 


\begin{tabular}{|c|c|c|c|c|c|c|}
\hline \multirow[b]{2}{*}{ Parameters } & \multicolumn{6}{|c|}{ Pulse Sequences* } \\
\hline & $\begin{array}{l}\text { Coronal } \\
\text { Single-Shot } \\
\text { Fast SE }\end{array}$ & $\begin{array}{c}\text { Axial Single-Shot } \\
\text { Fast SE }\end{array}$ & $\begin{array}{l}\text { Sagittal } \\
\text { Single-Shot } \\
\text { Fast SE }\end{array}$ & $\begin{array}{c}\text { Axial 2D FS } \\
\text { Single-Shot } \\
\text { Fast SE }\end{array}$ & $\begin{array}{c}\text { IP and OP } \\
\text { 2D T1W GRE }\end{array}$ & 2D TOF \\
\hline Sequence type & Single shot & Single shot & Single shot & Single shot & GRE & GRE \\
\hline $\begin{array}{l}\text { Repetition time } \\
\text { (msec) }\end{array}$ & $800-1100$ & $800-1100$ & $800-1100$ & $800-1100$ & 205 & 5500 \\
\hline Echo time (msec) & 60 & 60 & 60 & 60 & $2.2 / 4.5$ & 100 \\
\hline $\begin{array}{l}\text { Flip angle } \\
\text { (deorees) }\end{array}$ & $130-155$ & $130-155$ & $130-155$ & & 80 & 45 \\
\hline No. of signals ac- & & & $150-153$ & $130-133$ & & \\
\hline quired & 1 & 1 & 1 & 1 & 1 & 1 \\
\hline $2 \mathrm{D}$ or $3 \mathrm{D}$ & $2 \mathrm{D}$ & $2 \mathrm{D}$ & $2 \mathrm{D}$ & $2 \mathrm{D}$ & $2 \mathrm{D}$ & $2 \mathrm{D}$ \\
\hline Section thickness & & & & & & \\
\hline$(\mathrm{mm})$ & 4 & 4 & 4 & 4 & 5 & 3 \\
\hline Gap (mm) & 1 & 1 & 1 & 1 & 2 & 1 \\
\hline Field of view & & & & & & \\
\hline (mm) & 350 & 350 & 350 & 350 & 350 & 350 \\
\hline No. of partitions & & & & & & \\
\hline or sections & 20 & 20 & 20 & 20 & 32 & $\begin{array}{r}24 \\
\text { Axial }\end{array}$ \\
\hline $\begin{array}{l}\text { Orientation } \\
\text { Phase } \times \text { fre- }\end{array}$ & Coronal & Axial & Sagittal & Axial & Axial & Axial \\
\hline $\begin{array}{l}\text { quency steps } \\
\text { Rectangular field }\end{array}$ & $192 \times 256$ & $192 \times 256$ & $192 \times 256$ & $192 \times 256$ & $160 \times 256$ & $128 \times 256$ \\
\hline of view & No & 0.75 & 0.75 & 0.75 & 0.75 & 0.75 \\
\hline Fat suppression & No & No & No & Yes & No & No \\
\hline Zero fill section & No & No & No & No & No & No \\
\hline Partial Fourier & Yes & Yes & Yes & Yes & No & No \\
\hline $\begin{array}{l}\text { No. of measure- } \\
\text { ments or re- } \\
\text { peats }\end{array}$ & 1 & 1 & 1 & 1 & 1 & 1 \\
\hline $\begin{array}{l}\text { Single or multiple } \\
\text { shots }\end{array}$ & Single & Single & Single & Single & Multiple & Multiple \\
\hline Echo train length & $\ldots$ & $\cdots$ & $\cdots$ & $\cdots$ & $\ldots$ & $\ldots$ \\
\hline Bandwidth $(\mathrm{kHz}) t$ & 62.5 & 62.5 & 62.5 & 62.5 & 62.5 & 31.25 \\
\hline Parallel imaging & No & No & No & No & No & No \\
\hline Breath hold & Yes & Yes & Yes & Yes & Yes & Yes \\
\hline
\end{tabular}

Table 5: MR Imaging Protocol for Pregnant Patients with Acute RLQ Pain

\section{Urinary Tract Disorders}

Nephro- and ureterolithiasis represent the most common causes of abdominal pain of urologic origin.

US is frequently used as a screening examination, as US is a sensitive and specific test for diagnosing hydronephrosis and does not expose the patient or fetus to ionizing radiation. ${ }^{22-24}$ However, the differential diagnosis of hydronephrosis in the pregnant patient is confounded by physiologic hydronephrosis of pregnancy, which is thought to be caused by compression of the ureters between the gravid uterus and the linea terminalis. $25 \quad$ Physiologic hydronephrosis of pregnancy occurs in $>80 \%$ of pregnant women, more commonly occurs on the right than the left, and is generally seen beginning in the second trimester. ${ }^{25}$ Low-dose NCCT has been shown to be a sensitive and specific test for diagnosing stones in pregnant patients

Visualization of stones in the urinary tract is challenging with MR imaging, particularly intrarenal stones and those at the ureterovesical junction. 


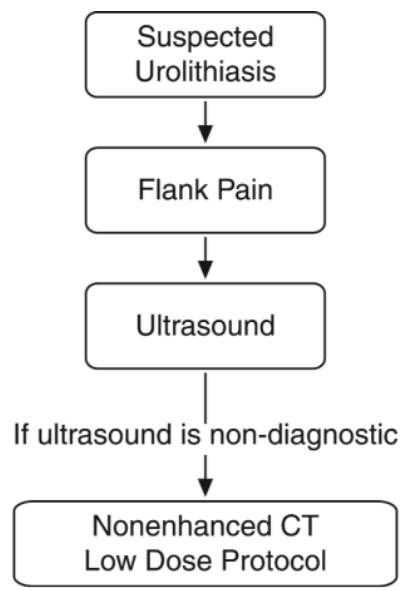

Figure 5: Diagnostic algorithm for suspected urolithiasis.

Clinical Condition: Acute Onset Flank Pain-Suspicion of Stone Disease (Urolithiasis) Variant 3: Pregnant patient.

\begin{tabular}{|c|c|c|c|}
\hline Radiologic Procedure & Rating & Comments & RRL* \\
\hline $\begin{array}{l}\text { US color Doppler kidneys and bladder } \\
\text { retroperitoneal } \\
\text { CT abdomen and pelvis without IV } \\
\text { contrast }\end{array}$ & $\begin{array}{l}8 \\
6\end{array}$ & & $\begin{array}{c}0 \\
909\end{array}$ \\
\hline $\begin{array}{l}\text { MRI abdomen and pelvis without IV } \\
\text { contrast }\end{array}$ & 5 & & o \\
\hline $\begin{array}{l}\text { CT abdomen and pelvis without and with } \\
\text { IV contrast }\end{array}$ & 2 & & 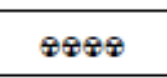 \\
\hline CT abdomen and pelvis with IV contrast & 2 & & कิด \\
\hline X-ray abdomen and pelvis (KUB) & 2 & & Q9 \\
\hline Radiography intravenous urography & 1 & & क्षि \\
\hline $\begin{array}{l}\text { MRI abdomen and pelvis without and with } \\
\text { IV contrast }\end{array}$ & 1 & & o \\
\hline \multicolumn{3}{|c|}{ Rating Scale: $1,2,3$ Usually not appropriate; 4,5,6 May be appropriate; $7,8,9$ Usually appropriate } & $\begin{array}{l}{ }^{*} \text { Relative } \\
\text { Radiation Level }\end{array}$ \\
\hline
\end{tabular}

Table 6: ACR. Imaging appropriateness in suspected urolithiasis in pregnant patient.

\section{Iodinated contrast media in pregnancy}

In general, intravascular contrast media should be avoided in pregnancy, in order to avoid any possible hazard to the fetus. In vitro experiments have shown iodinated contrast to be mutagenic to human cells. 26 Reassuringly, animal studies have failed to show an in vivo teratogenic effect. 27,28 The iodine content of contrast media has the potential to produce neonatal hypothyroidism, and this has been observed after the direct instillation of ionic contrast into the amniotic cavity during amniofetography. ${ }^{29}$ The intravascular use of non-ionic contrast media has been reported to have no effect on neonatal thyroid function. ${ }^{30}$ It is standard pediatric practice to screen all neonates for hypothyroidism, but it is particularly important to perform this test in the infants of mothers who received iodinated contrast during pregnancy. ${ }^{31}$

\section{Gadolinium contrast in pregnant patients}

The conclusion of a recent large cohort study from Ontario, Canada (Ray JG et al. JAMA. 2016;316(9):952-961) states, "Exposure to MRI during the first trimester of pregnancy compared with 
nonexposure was not associated with increased risk of harm to the fetus or in early childhood. Gadolinium MRI at any time during pregnancy was associated with an increased risk of a broad set of rheumatological, inflammatory, or infiltrative skin conditions and for stillbirth or neonatal death.

Intravenous gadolinium is teratogenic in animal studies. ${ }^{32}$ While teratogenic effects have not been observed in a small number of human studies where gadolinium has been given in pregnancy, 33,34 it is clear that gadolinium should not be administered in pregnancy unless there is an absolutely essential clinical indication, particularly during the period of organogenesis. Administration of gadolinium later in pregnancy may be reasonable, although such indication would likely be for a maternal or obstetric indication rather than for evaluation of a fetal abnormality. Examples might include gadolinium enhanced imaging for a maternal brain tumor or suspected placenta accreta. Gadolinium crosses the placenta where it is presumably excreted by the fetal kidneys into the amniotic fluid. In the era of gadolinium-induced nephrogenic systemic fibrosis, this raises theoretical concerns of toxicity related to disassociation and persistence of free gadolinium. Such concerns reinforce the regulatory advice on gadolinium use in pregnancy. The 2007 ACR guidance document for safe MRI practices recommends that intravenous gadolinium should be avoided during pregnancy and should only be used if absolutely essential; furthermore, the risks and benefits of gadolinium use must be discussed with the pregnant patient and referring clinician. 35 Gadolinium is classified as a category C drug by the Food and Drug Administration and can be used if considered critical (only to be administered "if the potential benefit justifies the potential risk to the fetus").

The American College of Gynecology and Obstetrics recommends that pregnant patients should be reviewed on a case-to-case basis, and the riskbenefit ratio needs to be made by the physicians involved. There are no known biological effects of MRI on fetuses. Gadolinium should be avoided when examining a pregnant patient.

\section{Conclusions}

Modalities that do not use ionizing radiation, such as US and MR imaging, should be the preferred examinations for evaluating an acute condition in a pregnant patient. However, no examination should be withheld when an important clinical diagnosis is under consideration. Exposure to ionizing radiation may be unavoidable, but there is no evidence to suggest that the risk to the fetus after a single imaging study and an interventional procedure is significant. All efforts should be made to minimize the exposure, with consideration of the risk versus benefit for a given clinical scenario. 


\section{References}

1. Coakley FV, Glenn OA, Qayyum A, Barkovich AJ, Goldstein R, Filly RA. Fetal MRI: a developing technique for the developing patient. AJR Am J Roentgenol 2004;182(1):243-252.

2. Wagner LK, Lester RG, Saldana LR. Exposure of the pregnant patient to diagnostic radiations: a guide to medical management. 2nd ed. Madison, Wis: Medical Physics, 1997.

3. Brent RL. Saving lives and changing family histories: appropriate counseling of pregnant women and men and women of reproductive age, concerning the risk of diagnostic radiation exposures during and before pregnancy. Am J Obstet Gynecol 2009;200(1): 4-24.

4. Bushberg JT. The essential physics of medical imaging. 2nd ed. Philadelphia, Pa: Lippincott Williams \& Wilkins, 2002.

5. Wieseler $\mathrm{KM}^{1}$, Bhargava P, Kanal KM, Vaidya S, Stewart BK, Dighe MK. Imaging in pregnant patients: examination appropriateness.Radiographics. 2010 Sep;30(5):1215-29; discussion 1230-3. doi: 10.1148/rg.305105034.

6. American College of Radiology. $\mathrm{ACR}$ practice guideline for imaging pregnant or potentially pregnant adolescents and women with ionizing radiation.
Reston, Va: American College of Radiology, 2008

7. Patel SJ, Reede DL, Katz DS, Subramaniam R, Amorosa JK. Imaging the pregnant patient for nonobstetric conditions: algorithms and radiation dose considerations. RadioGraphics 2007;27(6): 1705-1722.

8. Martin JN Jr, Ridgway LE 3rd, Connors JJ, Sessums JK, Martin RW, Morrison JC. Angiographic arterial embolization and computed tomography-directed drainage for the management of hemorrhage and infection with abdominal pregnancy. Obstet Gynecol 1990;76(5 pt 2):941-945.

9. Bushberg JT. X-ray interactions. RadioGraphics 1998;18(2):457468.

10. Toglia MR, Weg JG. Venous thromboembolism during pregnancy. N Engl J Med 1996; 335:108-114.

11. Knight M. Antenatal pulmonary embolism: risk factors, management and outcomes. BJOG 2008; 115:453-461.

12. Winer-Muram HT, Boone JM, Brown HL, Jennings SG, Mabie WC, Lombardo GT. Pulmonary embolism in pregnant patients: fetal radiation dose with helical CT. Radiology 2002;224:487-492.

13. British Thoracic Society Standards of Care Committee Pulmonary Embolism Guideline Development Group. British Thoracic Society guidelines for 
the management of suspected acute pulmonary embolism. Thorax 2003; 58:470-483.

14. Schuster ME, Fishman JE, Copeland JF, Hatabu H, Boiselle PM. Pulmonary embolism in pregnant patients: a survey of practices and policies for CT pulmonary angiography. AJR Am J Roentgenol 2003; 181:14951498.

15. Stein PD, Woodard PK, Weg JG, et al. Diagnostic pathways in acute pulmonary embolism: recommendations of the PIOPED II investigators. Radiology 2007; 242:15-21.

16. Pahade JK ${ }^{1}$, Litmanovich D, Pedrosa I, Romero J, Bankier AA, Boiselle PM.

Radiographics. Quality initiatives: imaging pregnant patients with suspected pulmonary embolism: what the radiologist needs to know.2009 May-Jun;29(3):639-54. doi: 10.1148/rg.293085226. Epub 2009 Mar 30.

17. Leung AN, Bull TM, Jaeschke $\mathrm{R}$, Lockwood CJ, Boiselle PM, Hurwitz LM, James AH, McCullough LB, Menda Y, Paidas MJ, Royal HD, Tapson VF, Winer-Muram

HT, Chervenak FA, Cody DD, McNitt-Gray MF, Stave CD, Tuttle BD; ATS/STR Committee on Pulmonary Embolism in Pregnancy. An official American Thoracic
Society/Society of Thoracic Radiology clinical practice guideline: evaluation of suspected pulmonary embolism in pregnancy. Am J Respir Crit Care Med. 2011 Nov 15;184(10):1200-8. doi: 10.1164/rccm.201108-1575ST.

18. Parker MS, Hui FK, Camacho MA, Chung JK, Broga DW, Sethi NN. Female breast radiation exposure during CT pulmonary angiography. AJR Am J Roentgenol 2005; 185:1228-1233.

19. Rehani MM, Berry M. Radiation doses in computed tomography: the increasing doses of radiation need to be controlled. BMJ 2000; 320:593-594.

20. Nickoloff EL, Alderson PO. Radiation exposures to patients from CT: reality, public perception, and policy. AJR Am J Roentgenol 2001; 177:285-287

21. Andersen B, Nielsen TF. Appendicitis in pregnancy: diagnosis, management and complications. Acta Obstet Gynecol Scand 1999;78(9):758762.

22. Cappell MS, Friedel D. Abdominal pain during pregnancy. Gastroenterol Clin North Am 2003;32 (1):1-58.

23. Wieseler KM, Bhargava P, Kanal KM, Vaidya S, Stewart BK, Dighe MK. Imaging in pregnant patients: examination appropriateness. Radiographics. 
2010;30(5):1215-1229; discussion 1230-1213.

24. Masselli G, Derme M, Laghi F, et al. Imaging of stone disease in pregnancy. Abdom Imaging. 013;38(6):1409-1414.

25. McAleer SJ, Loughlin KR. Nephrolithiasis and pregnancy. Curr Opin Urol. 2004;14(2):123127.

26. Rasmussen PE, Nielsen FR. Hydronephrosis during pregnancy: a literature survey. Eur J Obstet Gynecol Reprod Biol. 1988;27(3):249-259.

27. Nelson JA, Livingston JC, Moon RG. Mutagenic evaluation of radiographic contrast media. Invest Radiol 1982; 17: 183-185.

28. Morisetti A, Tirone P, Luzzani F, de Haen $C$. Toxicologic safety assessment of iomeprol, a new $\mathrm{x}$ ray contrast agent. Eur J Radiol 1994; 18 (Suppl 1): 21-31.

29. Ralston WH, Robbins MS, James P. Reproductive, developmental, and genetic toxicity of ioversol. Invest Radiol 1989; 24 (Suppl 1): 16-22.

30. Desch F, Camus M, Ermans AM, et al. Adverse effects of amniofetography on fetal thyroid function. Am J Obstet Gynecol 1976; 126: 723-726.

31. Na G, Zaffaroni M, Defilippi C, et al. Effects of iopamidol on neonatal thyroid function. Eur J Radiol 1992; 12: 22-25.
32. Webb JA, Thomsen HS, Morcos SK; Members of Contrast Media Safety Committee of European Society of Urogenital Radiology (ESUR). The use of iodinated and gadolinium contrast media during pregnancy and lactation. Eur Radiol 2005; 15: 1234-1240.

33. Okuda Y, Sagami F, Tirone P, Morisetti A, Bussi S, Masters RE. Reproductive and developmental toxicity study of gadobenate dimeglumine formulation (E7155) (3) --Study of embryo-fetal toxicity in rabbits by intravenous administration. J Toxicol Sci 1999;24 (Suppl 1): 79-87.

34. Marcos HB, Semelka RC, Worawattanakul S. Normal placenta: gadolinium-enhanced dynamic MR imaging. Radiology. 1997; 205: 493-6.

35. Spencer JA, Tomlinson AJ, Weston MJ, Lloyd SN. Early report: comparison of breathhold MR excretory urography, Doppler ultrasound and isotope renography in evaluation of symptomatic hydronephrosis in pregnancy. Clin Radiol. 2000;55: 446-53.

36. Kanal E, Barkovich AJ, Bell C, Borgstede JP, Bradley WG, Jr., Froelich JW, et al. ACR guidance document for safe MR practices: 2007. AJR Am J Roentgenol 2007; 188: 1447-74. 